\title{
Monitoring of cerebral function after severe asphyxia in infancy
}

\author{
I BJERRE, L HELLSTRÖM-WESTAS, I ROSÉN, AND N SVENNINGSEN \\ Department of Clinical Neurophysiology and Neonatal Intensive Care Unit, \\ Department of Paediatrics, University Hospital, Lund, Sweden
}

SUMMARY Thirty nine infants with severe asphyxia (28 affected perinatally and 11 later) were studied by electrophysiological cerebral function monitoring (CFM) for periods varying from a half to 49 days. Nineteen infants died while still in intensive care and two died later from sequelae. Eighteen survived and were followed up when aged between 8 and 36 months. The initial electroencephalogram (EEG) and the first 12 hours of CFM tracing correlated well. The type of background activity, whether continuous or interrupted, proved to be of high prognostic importance unlike the presence of seizure activity, which bore no distinct correlation to outcome in these severely asphyxiated infants.

Severe asphyxia in the perinatal period and in early infancy may have unfavourable short and long term consequences. ${ }^{1-3}$ Neurological symptoms such as convulsions, hypotonia, or lethargy may indicate the degree of risk of early death or later neurodevelopmental sequelae. ${ }^{4} 5$

The difficulties of basing the prognosis on neuroogical examinations alone, however, have been described in earlier studies. ${ }^{6}{ }^{7}$ The value of cranial computed tomography and electroencephalography (EEG) as predictors of clinical outcome has been disputed. Holmes et al, however, recently reported background activity in EEG as a valuable diagnostic and prognostic tool. ${ }^{8}$ Conventional EEG recordings can usually be made only for short periods of time. In order to follow the cerebral activity during a longer period we applied a new technique for cerebral function monitoring (CFM), which has been described by Prior. ${ }^{9}$ In this investigation we undertook to evaluate the CFM method compared with conventional EEG recordings in infants with severe asphyxia. Our aim was to estimate the diagnostic and prognostic value of CFM and to assess its value in neonatal intensive care management.

\section{Patients and methods}

We studied 39 infants treated in the neonatal intensive care unit in Lund between 1 December 1978 and 31 October 1982. All infants had been exposed to severe cerebral hypoxia either intra partum (28 infants) or later during infancy (11). They were divided into three groups according to maturity. Group 1 comprised 13 term infants, group 2 comprised 15 preterm infants, and group 3 comprised 11 infants with late asphyxia (age range 1 day-5 months). Table 1 gives some of the clinical characteristics shown in the three groups. Seven infants in group 3 had developed near miss sudden infant death syndrome; the other four had had long hypoxic periods for various reasons including severe infection.

Table 1 Clinical characteristics in three groups of infants with severe asphyxia

\begin{tabular}{|c|c|c|c|c|c|c|c|c|c|}
\hline & $\begin{array}{l}\text { Total } \\
\text { no }\end{array}$ & $\begin{array}{l}\text { No of } \\
\text { deaths }\end{array}$ & $\begin{array}{l}\text { Gestational } \\
\text { age }(w k s)\end{array}$ & $\begin{array}{l}\text { Mean } \\
\text { score } \\
1 \text { min }\end{array}$ & $\begin{array}{l}\text { Apgar } \\
\qquad 5 \text { mins }\end{array}$ & 10 mins & $\begin{array}{l}\text { No requiring } \\
\text { mechanical } \\
\text { ventilation }\end{array}$ & $\begin{array}{l}\text { Mean age (range) } \\
\text { at death } \\
\text { (months) }\end{array}$ & $\begin{array}{l}\text { Mean age (range) } \\
\text { at follow up } \\
\text { (months) }\end{array}$ \\
\hline $\begin{array}{l}\text { Group } 1 \\
\text { Perinatal asphyxia } \\
\text { in term infants }\end{array}$ & 13 & 5 & $38-42$ & $2 \cdot 1$ & $4 \cdot 3$ & $5 \cdot 6$ & 12 & $0.8(0-1)$ & $12 \cdot 7(8-21)$ \\
\hline $\begin{array}{l}\text { Group } 2 \\
\text { Perinatal asphyxia in: } \\
\text { Moderately preterm infants } \\
\text { Very preterm infants }\end{array}$ & $\begin{array}{l}6 \\
9\end{array}$ & $\begin{array}{l}2 \\
4\end{array}$ & $\begin{array}{l}32-37 \\
26-31\end{array}$ & $\begin{array}{l}1 \cdot 7 \\
2 \cdot 9\end{array}$ & $\begin{array}{l}4 \cdot 8 \\
3 \cdot 9\end{array}$ & $\begin{array}{l}6 \cdot 2 \\
5 \cdot 4\end{array}$ & $\begin{array}{l}5 \\
8\end{array}$ & $\begin{array}{l}1(1) \\
0 \cdot 5(0-2)\end{array}$ & $\begin{array}{l}22 \cdot 0(9-36) \\
19 \cdot 4(12-30)\end{array}$ \\
\hline $\begin{array}{l}\text { Group } 3 \\
\quad \text { Late asphyxia (1d-5 mths) }\end{array}$ & 11 & 8 & $34-42$ & $8 \cdot 6$ & $9 \cdot 7$ & $10 \cdot 0$ & 10 & $2 \cdot 5(0-12)$ & $12 \cdot 0(11-15)$ \\
\hline
\end{tabular}


All infants were nursed in incubators, and 35 received mechanical ventilation. In each case pulse, respiration, temperature, and blood pressure were monitored continuously as were arterial and transcutaneous oxygen tensions. Treatment of asphyxia also included early treatment with anticonvulsants. ${ }^{10}$ This was given to 25 infants almost all of whom were in groups 1 and 3. After a loading dose of $10 \mathrm{mg} / \mathrm{kg}$ body weight, phenobarbitone was administered $10 \mathrm{mg} / \mathrm{kg}$ in two doses over 24 hours. If convulsions developed in spite of this, diazepam 1-2 $\mathrm{mg} / \mathrm{kg}$ body weight was administered intravenously; finally, if necessary, patients were given lidocaine in an initial dose of $2 \mathrm{mg} / \mathrm{kg}$ body weight with $4-6 \mathrm{mg} / \mathrm{kg} / \mathrm{hour}$ thereafter tailing off over 24-36 hours. Serum concentrations of phenobarbitone were measured frequently.

Electroencephalography with a Mingograph EEG-10 (Siemens-Elema) was started on clinical indications of severe asphyxia followed by neuro-

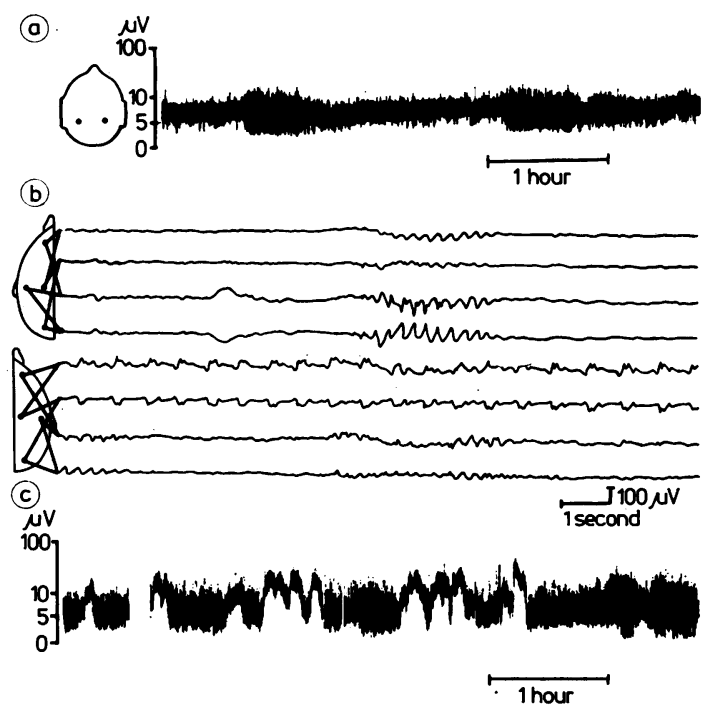

Fig. 1 (a) Initial CFM tracing showing continuous activity with periods of enhanced amplitude fluctuations reflecting periods of deep sleep (trace alternant).

(b) EEG showing continuous paroxysmal activity over right central area and bursts of independent paroxysmal activity over left occipitotemporal region.

(c) CFM tracing (same patient as the EEG in b) showing several periods of ictal activity of approximately 10 minutes duration each, illustrated by a sudden increase of the CFM amplitude level. After lidocain infusion the activity change to suppression burst pattern (at end of trace).

EEG program used: 1: Fpl-C3, 2: C3-01, 3: Fpl-T3, 4: T3-01, 5: Fp2-C4, 6: C4-02, 7: Fp2-T4, 8: T4-02. logical symptoms such as hypotonia, irritability, or convulsions. Longitudinal and transverse bipolar records as well as monopolar records were made with needle or disc electrodes (Fig. 1 (b)). Initial EEG was of 20-30 minutes duration and recorded cerebral function both at rest and during activation by, for example, loud sounds or pinching. The age of the infants at the time of the initial EEG ranged from a few hours to several months (Table 2).

In 29 children cerebral function monitoring (CFM) was started directly after initial EEG, but in three the CFM was applied before and in 6 patients one to 14 days after EEG. In one child no EEG record was made. Long intervals between the hypoxic incident and EEG, and also between the initial EEG and CFM, occurred, mainly in the group of preterm infants.

The CFM tracings were made with a cerebral function monitor (CFMTM, Devices Limited) according to the method of Prior. ${ }^{9}$ The CFM derives its signals from a single pair of parietal electrodes. A filter selects frequencies between 2 and $15 \mathrm{~Hz}$ before the signal is written out as a trace on a separate slow speed chart recorder. As cerebral activity fluctuates the pen moves up and down. The paper speed used is $6 \mathrm{~cm} /$ hour, and the trace appears as a thick band on the chart. The lower edge of the band represents the minimum degree of cerebral activity. Figs. 1 and 2 show examples of such tracings. The tracings varied in duration from 12 hours -49 days, median four-five days.

The first and last 12 hours of the CFM record and the initial EEG were interpreted by the Department of Clinical Neurophysiology, as part of this study, without knowledge of the outcome of the infant. The EEG was classified as continuous, (with continuous cerebral activity) or interrupted (suppression burst activity or no identifiable cortical activity). The presence of paroxysmal activity was also noted and classified as ictal or interictal. Fig. 1(b) shows paroxysmal EEG activity of ictal type.

The CFM tracings were likewise classified as continuous or interrupted and the presence or absence of ictal paroxysmal activity was noted. Fig. 1(a) shows normal cortical activity with fluctuations with sleeping and waking in the CFM.

Table 2 Age at first EEG in the three groups. (Infants with late asphyxia underwent EEG not more than one day after asphyxia in all cases)

\begin{tabular}{llll}
\hline & $0-1$ days & $2-3$ days & $>4$ days \\
\hline Group 1 & 9 & 2 & 2 \\
Group 2 & 4 & 5 & 5 \\
Group 3 & 1 & 1 & 9 \\
\hline
\end{tabular}


Fig. 2 also shows examples of continuous CFM tracings ( 8 and 12 days of age), severe depression (14 hours), and suppression burst activity of various degrees ( 2 and 4 days). Figs. 1(c) and 2 (1 day) show paroxysmal activity in CFM. If there was a change from interrupted to continuous activity from the first to the last 12 hour period of tracing, the entire tracing was scrutinised to discover at what time the change of pattern had taken place.

The outcome in each infant was evaluated from clinical records, and four categories were distinguished. These were healthy (no clinical symptoms or signs of brain damage at follow up), moderate or slight brain damage (such as slight psychomotor retardation or hemisyndrome), severe brain damage (such as tetraplegia or severe mental retardation with or without epilepsy), or dead before discharge from the neonatal intensive care unit.

The records were studied retrospectively, and the infants underwent follow up when aged between 8 and 36 months (median 12 months). Evaluation of the EEGs and CFM tracings and description of the clinical courses were undertaken independently by different members of the investigative team.

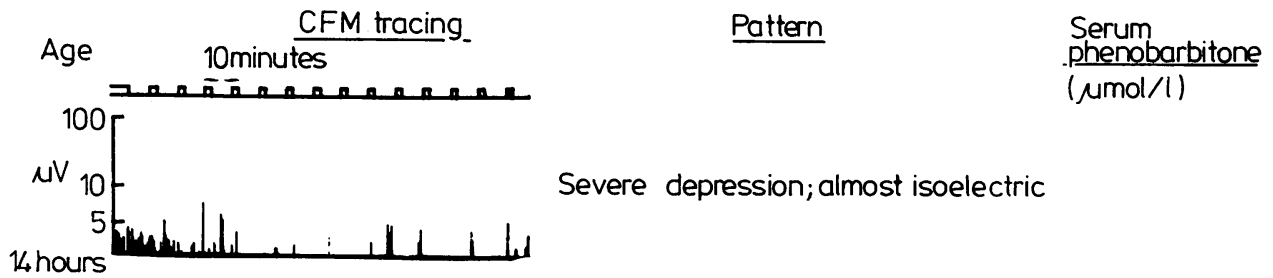

1day w. Weturn of EEG; paroxysmal activity

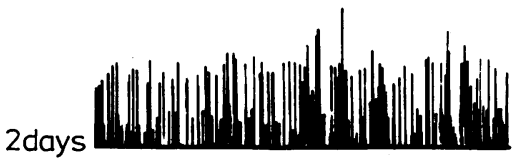

Suppression burst pattern; suppression dominant

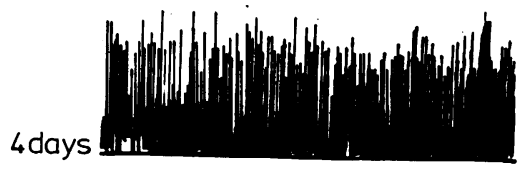

Suppression burst pattern; increased burst activity

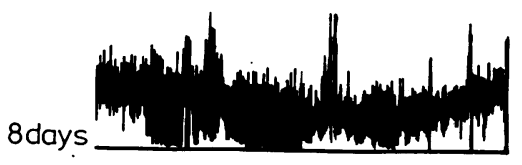

Continuous activity with suppression burst period

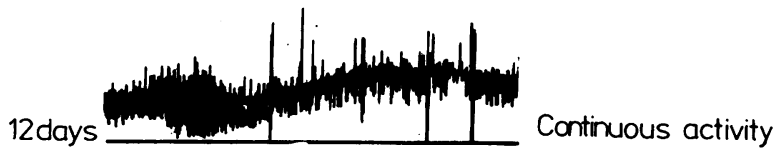

Fig. 2 CFM tracings from a continuous record over 12 days from one boy. (CFM display is on a logarithmic scale). 


\section{Results}

Concordance between CFM and EEG. There was an agreement in background activity between the first CFM tracing and the initial EEG in 35 infants (Table 3); in only three was there a discrepancy. In one of these the records were not made on the same day so electroencephalographic activity may have changed. In the other two patients interictal paroxysmal activity was seen in the EEG. This did not show up in the CFM tracing, which was interpreted as suppression burst activity. There was also good correlation between EEG and CFM in ictal paroxysmal activity, which was seen in 7 patients. Ictal paroxysmal activity in EEG or CFM did not always show as clinical convulsions, but infants with overt or suspected convulsions often had an interrupted CFM or EEG tracing (14 patients)-namely, a depressed curve with or without intermittent bursts.

CFM as a predictor of outcome. The characterisation of the CFM tracing as continuous or interrupted was important in predicting the outcome in the infant. Table 4 shows the type of CFM trace produced during the first and last 12 hour period of recording. Three infants underwent CFM for less than 24 hours and were not included-two, with continuous activity, were both healthy at follow up whereas the third showed severely depressed, interrupted activity and died within a few hours.

Eight infants showed continuous activity in both records (Table 4). At follow up four were healthy, two had brain damage, and two had died from causes other than hypoxic brain damage. The difference in prognostic importance between a continuous and an interrupted CFM record is further illustrated by the 18 infants who had interrupted background activity in both CFM tracings.

Table 3 Concordance between background activity recorded in CFM and EEG

\begin{tabular}{ll}
\hline & Number \\
\hline Continuous activity in both & 10 \\
Interrupted activity in both & 25 \\
Continuous EEG activity, interrupted CFM activity & 2 \\
Interrupted EEG activity, continuous CFM activity & 1 \\
EEG not recorded & 1 \\
\hline
\end{tabular}

None of these infants was healthy at follow up; 15 had died, and three survived with signs of brain damage. Nine infants made a recovery according to to the CFM tracings-that is, their CFM tracings changed from interrupted to continuous. At follow up four were healthy and five showed signs of cerebral damage. All tracings that changed from interrupted to continuous did so within 7 days (Table 5). Three of the four tracings in subsequently healthy infants changed within two days, as did tracings from two infants with brain damagesevere in one, slight in the other.

Only three children showing two interrupted tracings survived (Table 6); two, with only moderate cerebral damage, were extremely premature (gestational ages 26 and 27 weeks); the third developed severe brain damage caused by bacterial meningitis.

Fig. 2 shows how CFM followed the condition of a boy born at a gestational age of 36 weeks with severe asphyxia. His Apgar score was 0 at 1 minute and four at 5 and 10 minutes. He was intubated immediately, and received assisted ventilation and phenobarbitone $10 \mathrm{mg} / \mathrm{kg}$ body weight. At 14 hours of age the CFM tracing showed almost no cerebral activity. At one day old he had convulsions. Serum phenobarbitone concentration was then $113 \mu \mathrm{mol} / 1$ and the CFM tracing showed ictal paroxysmal activity. At two days of age lidocain was added to

Table 5 Correlation between time lapse of change in CFM activity from interrupted to continuous and outcome

\begin{tabular}{llll}
\hline $\begin{array}{l}\text { Time } \\
\text { (days) }\end{array}$ & Severe brain damage & $\begin{array}{l}\text { Moderatel } \\
\text { slight brain damage }\end{array}$ & Healthy \\
\hline $1-2$ & 1 & 1 & 3 \\
$3-4$ & 2 & & 1 \\
6 & 1 & & \\
\hline
\end{tabular}

Table 6 Outcome in infants with two interrupted CFM tracings

\begin{tabular}{llllll}
\hline & & Dead & $\begin{array}{l}\text { Severe brain } \\
\text { damage }\end{array}$ & $\begin{array}{l}\text { Moderate/slight } \\
\text { brain damage }\end{array}$ & Healthy \\
\hline Group 1 & $(\mathrm{n}=4)$ & 4 & 0 & 0 & 0 \\
Group 2 & $(\mathrm{n}=7)$ & 5 & 0 & $2 *$ & 0 \\
Group 3 & $(\mathrm{n}=7)$ & 6 & 1 & 0 & 0 \\
\hline
\end{tabular}

*Immature, born at 26 and 27 weeks of gestational age.

Table 4 Correlation between type of background activity in CFM and outcome

\begin{tabular}{lccc}
\hline Type of background activity in CFM & Dead & Severe brain damage & Moderate/slight brain damage \\
\hline Continuous in both recordings $(n=8)$ & $2 *$ & 1 & 1 \\
Interrupted in both recordings $(n=18)$ & 15 & 1 & 2 \\
Continuous in initial recording, changing to interrupted $(n=1)$ & 1 & 0 & 0 \\
Interrupted in initial recording, changing to continuous $(n=9)$ & 0 & $4 \dagger$ & 0 \\
\hline
\end{tabular}

*Death caused by myotonic dystrophy in one, meningoencephalitis ECHO 11 in the other.

$\uparrow$ Two died later with severe brain damage and infections. 
the anticonvulsive treatment. CFM now showed suppression burst tracing. At 4 days serum phenobarbitone concentration was $220 \mu \mathrm{mol} / 1$. In spite of this, the CFM tracing showed increasing burst activity. At 8 days serum phenobarbitone concentration was still high $(170 \mu \mathrm{mol} / \mathrm{l})$ but the CFM tracing had changed to show continuous activity with only some suppression burst periods. At 12 days cortical activity was continuous and serum phenobarbitone concentration $75 \mu \mathrm{mol} / \mathrm{l}$. He was severely brain damaged and died from pulmonary complications at 5 months of age.

Total paroxysmal activity was seen in 8 infants during the first 12 hours of CFM tracing. Two died, three survived with severe brain damage, and three were healthy at follow up. Out of 31 infants without signs of ictal paroxysmal activity during the first 12 hours of CFM recording, 20 died or survived with severe brain damage and 9 were either healthy or had slight brain damage at follow up. Thus, there does not seem to be a clear relation between ictal episodes in the first 12 hours of CFM tracings and clinical outcome.

Influence of serum phenobarbitone concentration. Serum phenobarbitone concentration was measured in 28 infants. The therapeutic range is $65-130 \mu \mathrm{mol} / 1$, but higher serum concentrations were aimed at as part of the programme for protecting the brain. Serum phenobarbitone was $<130 \mu \mathrm{mol} / 1$ in 19 infants at the first measurement. Five of these showed continuous and 14 interrupted CFM tracings. The serum phenobarbitone was $>130$ $\mu \mathrm{mol} / 1$ in 9 infants, all of whom showed interrupted CFM tracings. Serum phenobarbitone concentrations rose above $130 \mu \mathrm{mol} / 1$ during treatment in 12 patients, in 7 of whom CFM tracings remained interrupted; in three they changed from interrupted to continuous; in two they remained continuous. Thus, in spite of rising serum phenobarbitone concentrations no CFM tracings changed from continuous to interrupted.

Seven infants initially showed interrupted CFM tracings and high serum phenobarbitone concentrations $(>130 \mu \mathrm{mol} / \mathrm{l})$. Four of them died, all of whom had continued to show interrupted CFM tracings. Three survived, two of whose CFM tracings changed during recording from interrupted to continuous; one showed rising and one falling serum phenobarbitone concentrations. Thus the serum phenobarbitone concentrations within the ranges studied did not seem to have an important influence on the pattern of CFM tracings.

\section{Discussion}

Severe perinatal asphyxia may cause irreversible brain damage leading to death or serious neurological sequelae. It is important in modern neonatal intensive care to distinguish patients with a reasonable chance of healthy life or life with a handicap that can be compensated for. Morphometric $11{ }^{12}$ as well as neurophysiological techniques ${ }^{81314}$ and clinical rating ${ }^{4}$ have been proposed as useful diagnostic tools in this respect.

Our findings indicate that the EEG pattern, as reflected in the CFM record, and its changes during the first few days after asphyxia provide fairly stringent prognostic information. In agreement with earlier studies of $E E G,^{815}$ the background activity seen in CFM contains the most important information. A flat record or interrupted activity of suppression burst type uninfluenced by physical activity and not changing into a continuous record within a few days indicates a poor outcome. An interrupted EEG pattern is seen in very preterm, otherwise healthy, infants. ${ }^{16}$ It is not, therefore, surprising that two very immature infants, despite giving interrupted CFM records, survived with only slight or moderate sequelae.

The presence of ictal paroxysmal activity has been reported by some authors to give a poor prognosis, ${ }^{34}$ but others, like ourselves, have found it to be an indecisive prognostic factor. ${ }^{518}$ One explanation of this in our study could be that the patients received early and adequate antiepileptic treatment, which is thought to protect the brain. ${ }^{10}$

Barbiturates in high concentrations change EEG activity from a continuous to an interrupted pattern. ${ }^{17}$ Modern posthypoxic treatment with high doses of barbiturate may thus invalidate the EEG as a prognostic tool. Our results, as well as those of others, ${ }^{18}$ indicate that at the barbiturate concentrations used, the EEG and CFM patterns maintain their prognostic importance.

From earlier studies it is known that the brains of newborn babies respond to hypoxaemia by an initial slowing of the EEG activity followed by electrical silence in a similar way as in adults. The duration of flattening of the EEG associated with transient cerebral depression or permanent cerebral damage of newborn babies has not, however, been known previously. ${ }^{19}$ Our findings show that in this and other respects the CFM technique provides definite advantages in comparison with conventional EEG recordings. It can easily be continued for days and weeks with a maintained review of the material collected. Because it is easy to handle, the staff of our neonatal intensive care unit could initiate the monitoring at any time of the day. It is also much easier to correlate changes in the CFM record with fluctuations in the clinical condition such as seizures and changes of treatment. 
CFM does not, however, replace conventional multichannel EEG recording with regard to localisation and characterisation of epileptogenic foci, identification of asymetries, or characterisation of the frequency content of the EEG activity. We found it necessary to record a conventional EEG early during the CFM. This facilitates the interpretation of the CFM record. The CFM then reduces the need for repeated EEG during the course of treatment. CFM is a relatively easy and noninvasive method of continuously monitoring cerebral activity. We have shown that CFM is of diagnostic and prognostic value during intensive care treatment. It is of special value when the clinical condition of a patient is difficult to evaluate-for example, after heavy doses of antiepileptic treatment or during mechanical ventilation.

This investigation was supported by grants from Margarethahemmet, First of May Flower Annual Campaign for Children's Health and Jerring Research Foundations, and the Swedish Medical Research Council. (project no: 19X04732).

\section{References}

1 Finer NN, Robertson CM, Peters KL, Coward JH. Factors affecting outcome in hypoxic-ischemic encephalopathy in term infants. Am J Dis Child 1983;137:21-5.

2 deSouza SW, Richards B. Neurological sequelae in newborn babies after perinatal asphyxia. Arch Dis Child $1978 ; 53: 564-9$.

3 Volpe JJ. Perinatal hypoxic ischemic brain injury. Pediatr Clin North Am 1976;23:383-97.

4 Finer NN, Robertson CM, Richards RT, Pinnell LE, Peters KL. Hypoxic-ischemic encephalopathy in term neonates: perinatal factors and outcome. $J$ Pediatr $1981 ; 98: 112-7$.

5 Mulligan JC, Painter MJ, O'Donoghue PA, MacDonald HM, Allen AC, Taylor PM. Neonatal asphyxia. II. Neonatal mortality and long-term sequelae. J Pediatr $1980 ; 96: 903-7$.

6 Graziani LJ, Korberly B. Limitations of neurologic and behaviour assessment in the newborn infant. In: Gluck $L$, ed. Intrauterine asphyxia and the developing brain. Chicago: Year Book Medical Publishers, 1972:431-42.
7 Brown JK, Purvis RJ, Forfar JO, Cockburn F. Neurological aspects of perinatal asphyxia. Dev Med Child Neurol 1974;16:567-80.

8 Holmes G, Rowe J, Hafford J, Schmidt R, Testa M, Zimmerman A. Prognostic value of the electroencephalogram in neonatal asphyxia. Electroencephalogr Clin Neurophysiol 1982;53:60-72.

9 Prior P. Monitoring cerebral function. Long-term recordings of cerebral electrical activity. Amsterdam: North Holland Biomedical Press, 1979:45-301.

10 Svenningsen NW, Blennow G, Lindroth M, Gäddlin PO, Ahlström H. Brain-orientated intensive care treatment in severe neonatal asphyxia. Arch Dis Child 1982;57:176-83.

11 Fitzhardinge PM, Flodmark O, Fitz CR, Ashby S. The prognostic value of computed tomography as an adjunct to assessment of the term infant with postasphyxial encephalopathy. J Pediatr 1977;99:777-81.

12 Pape KE, Bennet-Britton S. Szymonowicz W, Martin DJ, Fitz CR, Becker L. Diagnostic accuracy of neonatal brain imaging: a postmortem correlation of computed tomography and ultrasound scans. J Pediatr 1983;102:275-80.

13 Hecox KE, Cone B. Prognostic importance of brainstem auditory evoked responses after asphyxia. Neurology $(N Y) 1981 ; 31: 1429-34$.

14 Watanabe K, Miyazake S, Hara K, Hakamada S. Behavioral state cycles, background EEGs and prognosis of newborns with perinatal hypoxia. Electroencephalogr Clin Neurophysiol 1980;49:618-25.

15 Coen RW, McCutchen CB, Wermer D, Snyder J, Gluck FE. Continuous monitoring of the electroencephalogram following perinatal asphyxia. $J$ Pediatr 1982;100:628-30.

16 Westmoreland BF, Stockard JE. The EEG in infants and children: normal patterns. American Journal of EEG Technology 1977;17:187-206.

17 Clark DL, Rosner BS. Neurophysiologic effects of general anesthetics: I. The electroencephalogram and sensory evoked responses in man. Anesthesiology 1973;38:564-82.

18 Staudt F, Schooll ML, Coen RW, Bickford RB. Phenobarbital therapy in neonatal seizures and the prognostic value of the EEG. Neuropediatrics 1982;13:24-33.

19 Robertson NRC. Effect of acute hypoxia on blood pressure and electroencephalogram of newborn babies. Arch Dis Child 1969;44:719-25.

Correspondence to Dr Ingmar Rosén, Department of Clinical Neurophysiology, University Hospital, S221 85 Lund, Sweden.

Received 22 September 1983 